\title{
Posttraining flavor exposure in hungry rats after simultaneous conditioning with a nutrient converts the CS into a conditioned inhibitor
}

\author{
David Garcia-Burgos • Felisa González
}

Published online: 1 October 2011

(C) Psychonomic Society, Inc. 2011

\begin{abstract}
The present study investigated the decrement in nutrient-based conditioned flavor preference found in hungry rats exposed to a flavor following simultaneous flavorsucrose conditioning while thirsty. Although a significant decrease in preference was found in the experimental group in each experiment, there was no evidence of either spontaneous recovery (Experiment 1) or reinstatement (Experiment 2). In addition, posttraining flavor exposure weakened the original flavor-sucrose association (Experiment 3). These results suggested that the flavor-US association might have been impaired after posttraining flavor exposure. Two further experiments assessed whether the flavor acquired the properties of a net inhibitor, using the retardation and summation tests for conditioned inhibition. Experiment 4 revealed that the flavor suffered retardation when retraining was conducted after the exposure phase. In Experiment 5, the target flavor decreased the preference shown for a different flavor previously paired simultaneously with sucrose when both were presented forming an unreinforced compound in the summation tests. None of these effects was found in a control group, which had received serial flavor $\rightarrow$ nutrient presentations during training. Together, these results suggest that a flavor simultaneously paired with sucrose acquires the properties of a net inhibitor when it is subsequently presented outside the compound to hungry animals.
\end{abstract}

Keywords Conditioned inhibition - Extinction $\cdot$ Flavor preference $\cdot$ Retardation test $\cdot$ Summation test

D. Garcia-Burgos • F. González ( $₫)$

Department of Experimental Psychology and

Physiology of Behavior, University of Granada,

Campus Cartuja s/n,

18071, Granada, Spain

e-mail: fgreyes@ugr.es
Conditioned flavor preference (CFP) is considered a form of Pavlovian conditioning (Rozin \& Schulkin, 1990; Rozin \& Zellner, 1985). A simple procedure for establishing this learning is to allow rats to drink a neutral flavor (the conditioned stimulus [CS]) paired with either a palatable second flavor (e.g., Holman, 1975) or a nutrient presented orally or intragastrically (e.g., Capaldi, Campbell, Sheffer, \& Bradford, 1987; Sclafani \& Nissenbaum, 1988), which serves as the unconditioned stimulus (US). These pairings result in a preference being established for the CS + (flavor paired with US) over CS- (flavor unpaired with US) (e.g., Drucker, Ackroff, \& Sclafani, 1994; Lucas \& Sclafani, 1989), as well as for the CS + over plain water (e.g., Harris, Gorissen, Bailey, \& Westbrook, 2000; Pérez, Lucas, \& Sclafani, 1998).

An unusual property attributed to learned flavor preferences, established either by combining the flavor with a palatable taste or by following ingestion of the flavor with a nutrient, is their resistance to extinction (e.g., Albertella \& Boakes, 2006; Capaldi, Myers, Campbell, \& Sheffer, 1983; Drucker et al., 1994; Elizalde \& Sclafani, 1990; Fedorchak, 1997; Sclafani, 1991). Nevertheless, it has been possible to observe the effects of flavor-alone presentations on CFP after conditioning with more sensitive testing procedures. Harris, Shand, Carroll, and Westbrook (2004, Experiments $2 \mathrm{~A}$ and $2 \mathrm{~B}$ ) examined conditioned preference in rats simultaneously exposed to a target flavor and sucrose and found a decrease in CFP measured by testing rats with a choice between flavor and water only when rats were deprived of food either during training or during testing. These findings suggest that presentations of the flavor alone following flavor preference conditioning seem not to be without effect, at least when a flavor is presented in compound with a palatable nutrient during conditioning (see also Delamater, 2007). 
One surprising finding revealed by this study is related to US devaluation results in subjects given extinction (Harris et al., 2004, Experiment 3). In this experiment, rats deprived of water throughout the experiment were given a simultaneous almond-sucrose compound during the conditioning stage. In the extinction stage, half the rats received exposure to almond across 20 trials, while the remaining rats were exposed to water. Then the consumption of sucrose solution was paired with i.p. injections of lithium chloride $(\mathrm{LiCl})$ for half of the rats in each of these conditions. Finally, rats were given an almond versus water choice test. The results showed that exposure to almond outside the compound after conditioning but before sucrose devaluation had an impact on the almond-sucrose association; the effect of the sucrose devaluation was itself reduced in the extinguished group, as compared with the nonextinguished group. Since stimuli given extinction are as sensitive to the devaluation procedure as those not extinguished (e.g., Rescorla, 1996), the rats given paired exposures to sucrose and $\mathrm{LiCl}$ (either extinguished or nonextinguished conditions) should have acquired a similar aversion to sucrose and rejected almond on test. The authors considered that the association between the flavor and the taste of sucrose was weakened during the flavor exposure. A similar result has been reported by Delamater (2007), who suggested that the associations formed between the flavor CS and the specific sensory properties of an orally presented nutrient US in thirsty rats (Experiment 1) and between the flavor CS and the motivational consequences of the nutrient (i.e., their calories) in hungry rats (Experiment 3) were weakened by extinction. However, given that the dominant view of experimental extinction is that it has no impact on the strength of the CS-US association (e.g., Bouton, 2004; Delamater, 1996; Rescorla, 1996; for reviews, see Delamater, 2004; Rescorla, 2001), Harris et al.'s (2004) and Delamater's (2007) conclusions are at odds with studies of extinction that have used more conventional learning paradigms.

Another surprising finding was reported by Higgins and Rescorla (2004) in a series of experiments with hungry rats throughout the experiments. In one of the groups, the flavor was presented alone after simultaneous flavor-nutrient training before being presented again paired with the nutrient (i.e., retraining). They found that although posttraining flavor exposure produced a decrease in flavor consumption, there was little indication that retraining produced reconditioning. Higgins and Rescorla (Experiment 3) compared the relative magnitudes of retraining with sequential and simultaneous conditioning. The results confirmed that reestablishing the flavor-nutrient relationship readily reestablished the response only in the case of sequential training, despite the fact that conditioning was more successful with simultaneous than with sequential presentation. However, it is assumed that when new CS-US pairings are introduced after extinction, the reacquisition of responding appears even more rapidly than the acquisition with a novel CS (e.g., Ricker \& Bouton, 1996).

Together, this empirical evidence raises doubts about whether extinction is in fact the source of the observed decrement in nutrient-based CFP when the flavor CS is exposed after simultaneous training with animals that are hungry. At the very least, it opens a door to alternative explanations that should be examined. One of them may be suggested in terms of a mechanism of perceptual differentiation suggested by Higgins and Rescorla (2004) to explain the failure in retraining observed in the group that received simultaneous conditioning with the auxiliary assumption of the subsequent acquisition by the flavor CS of net inhibitory properties during exposure. Since simultaneous conditioning involves presenting the flavor CS and the nutrient forming a compound, a unitary flavor-taste representation might have been formed during training (AT unitary representation of the compound, A being the flavor $\mathrm{CS}$ and $\mathrm{T}$ the taste of the nutrient). Subsequent separate presentations of the flavor (A-) may initially result in the animals' confusing it with the learned compound and responding accordingly. However, with repeated separate presentations, an additional representation of A may be formed, resulting in discrimination between the flavor and the compound. Thus, what appears to be initial associative learning could be the formation of a single compound representation, whereas what looks like extinction could be the formation of a separate representation of a component (Higgins \& Rescorla, 2004). Since a palatable nutrient has other features apart from the sensory properties of its taste, such as nutritive and affective properties (e.g., Delamater \& Oakeshott, 2007), the unitary sensory representation of the AT compound might initially enter into association with the affective and nutritive properties of the nutrient during training. Assuming that there is some generalization of the excitatory strength from the compound to the flavor in the first stages of posttraining flavor exposure, inhibitory learning may arise. Exposing A by itself without the nutrient during testing under hunger may activate the representation of the nutrient US, which would be absent at that moment, especially the postingestive actions of the nutrient (Harris et al., 2000) since rats are hungry. According to Wagner's (1981) model, an inhibitory association is formed when the CS representation activated into the A1 state (i.e., by the presentation of the stimulus) is associated with the US representation activated into the A2 state (i.e., activated by the presence of an associate cue). Therefore, if the presentation of the flavor alone activates its representation in A1 and, via generalization from the compound, produces an associative activation of the representation of the nutrient in A2 when animals are 
hungry, the flavor may become a signal of the absence of the postingestive actions of the nutrient; the flavor therefore might acquire net inhibitory properties. According to this proposal, the flavor may become a signal for the absence of the taste of sucrose and of its postingestive nutritive consequences, as well as of the hedonic reaction produced by the taste. Note that, following the suggestion of Higgins and Rescorla, the separate representation of the flavor forms only during posttraining exposure; therefore, the only association maintained with the US would be inhibitory, and thus the flavor would act as a net inhibitor and not as an extinguished stimulus, which should still retain the former excitatory association with the US.

Although the authors recognize that this proposal is rather speculative, it has, nonetheless, testable implications. For instance, if an inhibitory flavor CS-nutrient association, which endows the flavor with the properties of a net inhibitor, develops after posttraining flavor exposure, the US devaluation effect should not be expected, since the CS should not activate the representation of the US. Additionally, phenomena of recovery of the conditioned response after flavor exposure would not be expected either. More interestingly, if the flavor becomes a net inhibitor, it should pass both the summation and retardation tests for conditioned inhibition (Rescorla, 1969).

Therefore, the purpose of the present experiments was to provide further investigation on the nature of the decrease in CFP in hungry rats observed following presentations of the CS flavor alone after simultaneous flavor-nutrient training. In each experiment, rats were trained thirsty and subsequently exposed to the flavor while hungry. These conditions were used because, according to Harris et al.'s (2004, Experiment 2B) study, they should produce a decrease in conditioned preference. Given that our account relies on the formation of a unitary flavor-taste compound representation during conditioning, as well as on the formation of a separate representation of the flavor during posttraining flavor exposure, rats in the experimental group (simultaneous) were exposed to a flavor-sucrose compound during the conditioning phase. As a control condition, we used a serial group where rats were given the same amounts of the target flavor and sucrose, but without the possibility of forming a unitary flavor-US representation, since flavor and sucrose were presented several seconds apart (i.e., the time elapsed between the removal of each flavor tube and the insertion of the sucrose tubes).

In the present study, Experiments 1 and 2 assessed the phenomena of spontaneous recovery and reinstatement, whereas Experiment 3 examined the specificity of the effect of posttraining flavor exposure on particular components of the flavor US learning using the US devaluation technique. Finally, empirical evidence of inhibitory learning using retardation (Experiment 4) and summation tests (Experiment 5) for conditioned inhibition was examined. If the decrease in preference considered in these experiments is due not to mere extinction of the conditioned preference response, but to the development of net conditioned inhibition, neither recovery of flavor preference nor a US devaluation effect should be observed; additionally, the flavor should pass both the retardation and the summation tests.

\section{Experiment 1: Spontaneous recovery}

It is well established since Pavlov's time that the extinguished responses can recover if time is allowed to pass following extinction. The aim of this experiment was to evaluate whether the reduced preference after posttraining flavor exposure in hungry rats can be recovered following the passage of time. The design is shown in Table 1 (Experiment 1). Two groups of thirsty rats (simultaneous and serial) were trained during several daily sessions. The simultaneous group, given access to an almond-sucrose simultaneous compound, was compared with a serial group for which the sucrose solution was presented after the consumption of almond. The flavorexposure treatment was identical for each group and consisted of repeated two-bottle almond versus water tests while animals were hungry and thirsty. Thus, both groups
Table 1 Designs for spontaneous recovery and reinstatement experiments

$\mathrm{A}=\mathrm{CS}$ flavor; $+=$ US sucrose; Simultaneous $=$ group given almond-sucrose compound during conditioning phase; Serial $=$ control condition in which the sucrose solution was presented after the consumption of almond during conditioning phase

\begin{tabular}{llll}
\hline Groups & $\begin{array}{l}\text { Conditioning } \\
\text { Thirsty }\end{array}$ & $\begin{array}{l}\text { Pre-extinction } \\
\text { Thirsty \& Hungry }\end{array}$ & $\begin{array}{l}\text { Extinction } \\
\text { Thirsty \& Hungry }\end{array}$ \\
\hline
\end{tabular}

Experiment 1

Spontaneous recovery

( 2 weeks later)

Thirsty \& Hungry

Simultaneous $4 \mathrm{~A}+$

Serial $\quad 4 \mathrm{~A} \rightarrow+$

3 water vs. water

10 A vs. water

A vs. water

Experiment 2

Reinstatement

Thirsty \& Hungry

Simultaneous $4 \mathrm{~A}+\quad 3$ water vs. water $10 \mathrm{~A}$ vs. water $\quad+\quad$ A vs. water 
had an equivalent history of exposure to almond and sucrose but differed with respect to the CS-US temporal relationship during training - simultaneous or serial, respectively. Two weeks after the flavor exposure phase, subjects were tested for spontaneous recovery.

\section{Method}

Subjects and apparatus The subjects were 16 experimentally naïve female Wistar rats with a mean body weight of $247 \mathrm{~g}$ at the start of the experiment. Animals were housed in individual home cages and were kept in a large colony room maintained on a fixed 12:12-h light:dark cycle. This and all the subsequent experiments took place in the home cages, and they were conducted during the light cycle at approximately 9:30 a.m. Rats were water deprived throughout the experiment and were food deprived as detailed below. Fluids were administered at room temperature in a 50-ml plastic tube with a rubber stopper fitted with a stainless steel ball-bearing tipped spout, and fresh solutions were made every day. Consumption was estimated by weighing the tubes before and after fluid presentation to the nearest $0.1 \mathrm{~g}$. The solutions used were made up with tap water consisted of $1 \%(\mathrm{vol} / \mathrm{vol})$ almond (SuperCook, Leeds, U.K.), 20\% (wt/vol) sucrose, and 1\% almond and $20 \%$ sucrose compound. All the experimental procedures were approved by the University of Granada Ethics Committee and were in accordance with the European Communities Council Directive of 24 November 1986 (86/ 609/EEC).

Procedure Before the start of the experiment, the animals were assigned to two weight-matched groups $(n=8)$. The water bottles were removed from the home cages $24 \mathrm{~h}$ before the start of the experiment.

During the preconditioning phase (days 1-4), rats in both groups were given 4 days to accommodate to water deprivation. They were permitted to drink tap water for $30 \mathrm{~min}$ in the tubes subsequently used to present the flavored solutions.

During the conditioning phase (days 5-8), rats in the simultaneous group were given $6 \mathrm{ml}$ of the almond-sucrose compound for $5 \mathrm{~min}(6 \mathrm{ml}$ were provided to guarantee a 5 $\mathrm{ml}$ consumption to compensate for possible fluid spillage), whereas rats in the serial group were given $6 \mathrm{ml}$ of almond presented for $5 \mathrm{~min}$, followed by 5 -min access to $6 \mathrm{ml}$ of sucrose. After each conditioning session, all animals had access to supplementary water for $30 \mathrm{~min}$.

After the conditioning phase, animals were also food deprived by being given limited access to both water and food for 90 min per day at the end of each session. During days 911, the rats were given 3 days to accommodate to the food deprivation. Likewise, all groups received water in two tubes for $30 \mathrm{~min}$ on each of these 3 days to adapt them to the test conditions used in the extinction phase that was to follow.
The flavor exposure phase occurred over the next 10 days (days 12-21). All rats were given 10 two-bottle almond versus water tests for $30 \mathrm{~min}$, each bottle containing $20 \mathrm{ml}$ of the correspondent fluid. The position of the bottles was counterbalanced within each group and alternated across days. After the flavor exposure phase, food and water were returned to the home cages and were removed on day 31 . During days 32-34, rats were given 3 days to accommodate to food deprivation. On the 14th day after the flavor exposure phase (day 35), all groups received a two-bottle spontaneous recovery test under conditions identical to those used during the flavor exposure phase.

Statistical analysis For all the analyses, a significance level of $p<.05$ was adopted. The data were analyzed using analyses of variance (ANOVAs), followed by post hoc Tukey's tests, where appropriate, to determine the locus of significant main effects and interactions. Two-tailed $t$-tests were used to evaluate data not involving multiple comparisons. The test data for each rat were also converted into preference ratios, calculated as the intake of the target flavor over the total amounts consumed.

\section{Results}

Conditioning phase The mean daily intakes of almondsucrose compound consumed across the conditioning days were $2.56,5.72,5.9$, and $5.79 \mathrm{~g}$ for the simultaneous group. A similar pattern was found in the consumption of the almond solution (means: $4.95,5.67,5.57$, and 5.63 g.) and of the sucrose (means: $1.45,4.6,5.5$, and $5.61 \mathrm{~g}$.) in the serial group. These patterns suggest that fluids containing the almond and the sucrose solutions were affected by neophobia on the first trial, which disappeared on subsequent trials. Regarding differences between groups in the conditioning test (first flavor exposure test), the average preference ratio of the simultaneous group (.91) was significantly higher than that of the serial group $(.57), t(14)=12.33$, which did not differ from the preference reference value $.5, t(7)<1$.

Flavor exposure phase The results from the flavor exposure phase for almond preference and almond intake are shown in Fig. 1 (top and bottom left), demonstrating the mean ratio of almond preference and the mean intake of almond in both groups during this phase (2-day blocks). The 2 (group) $\times 5$ (block) ANOVA of the preference ratios revealed a marginally main effect of group, $F(1,14)=4.01, p=.06$, and a significant effect of block, $F(4,56)=7.62$, which, once analyzed, showed a decrement from block 1 to blocks 4 and 5. The data of most interest came from almond consumption, since the statistical analysis of water intake revealed neither a main effect of group, $F(1,14)=3.28$, or of block, $F<1$, nor 
Fig. 1 Experiment 1. Top left: Average preference ratio of almond (as ratio of almond intake over total intake) on each of the five exposure blocks of 2 days for the simultaneous (SIM) and serial (SER) groups. Top right: Average preference ratio of almond on the last exposure to almond (test 10) and day of spontaneous recovery test (14 days after). Bottom left: Average intake of almond on each of the five exposure blocks of 2 days for both groups. Bottom right: Average intake of almond on the last exposure to almond and day of spontaneous recovery test. Error bars represent SEMs
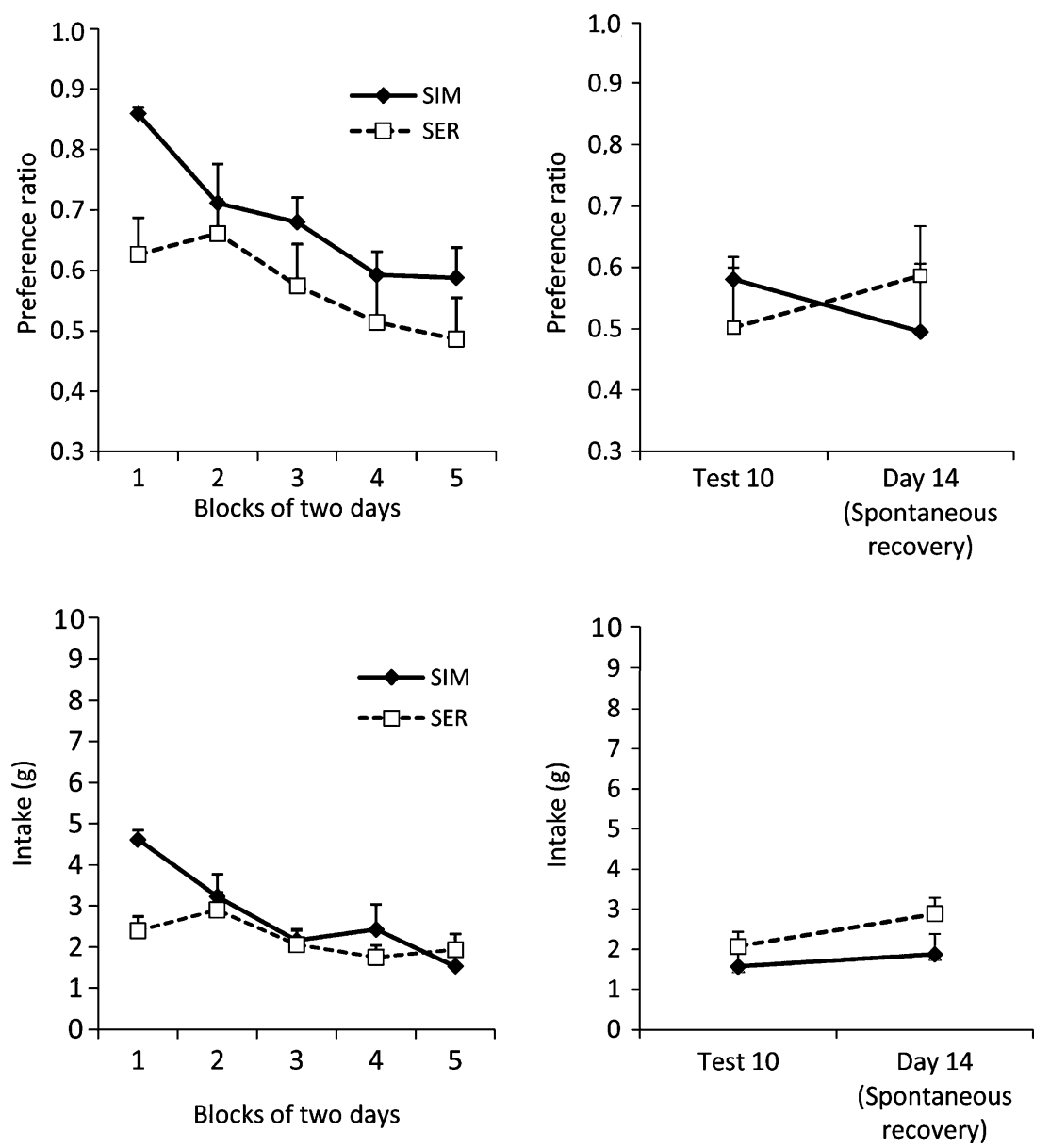

a group $\times$ block interaction, $F(4,56)=1.12$. The $2($ group $) \times$ 5 (block) ANOVA of the almond intake revealed a main effect of block, $F(4,56)=10.56$, and a significant group $\times$ block interaction, $F(4,56)=4.59$. The statistical analysis revealed that the simultaneous group exhibited significantly lower consumption of almond in blocks 3, 4, and 5 than in block 1 and that the serial group did not exhibit significant differences between blocks 1 and 5 but showed a higher almond intake in block 2, as compared with block 4. Finally, the simultaneous group exhibited higher almond consumption than did the serial group in block 1 .

Spontaneous recovery test The preference and almond intake results of the spontaneous recovery test can be found in Fig. 1 (top and bottom right). The two groups were tested for spontaneous recovery 14 days after flavor exposure, comparing the average preference ratio of the last test (test 10) with that of the spontaneous recovery test. The 2 (group) $\times 2$ (day) ANOVA of the preference ratios failed to detect any main effect or significant interaction, $F_{\text {s }}<1.17$. Similarly, the 2 (group) $\times 2$ (day) ANOVAs of the consumption revealed neither significant main effects nor interactions in either almond or water intake, $F_{\mathrm{S}}<2.6$.

\section{Discussion}

The analyses of the conditioning test showed that rats developed a preference for the flavor only when it was simultaneously paired with sucrose (simultaneous group). Although preference ratios did decrease in both groups, a more detailed inspection of fluid consumption revealed that almond intake differed from block 1 to blocks $3-5$ in the experimental group, whereas this was not the case for the serial group, which showed some fluctuations in almond consumption along this phase. No differences were found in water consumption.

Following a retention interval of 14 days, the almond solution was again pitted against water. There was no significant increase in the preference ratio or flavor intake when tested for spontaneous recovery. The absence of spontaneous recovery after a 2 -week interval replicates previous results obtained in our lab using mere exposure and unpaired control groups (González, de Brugada, \& Gil, 2008, Experiment 3).

This lack of spontaneous recovery is somewhat surprising, since it is a widespread phenomenon, in terms of both the variety of learning paradigms in which it happens and 
the frequency with which it is reported, including tastetaste learning (Díaz \& De la Casa, 2011), conditioned taste avoidance (e.g., Rosas \& Bouton, 1996), spatial preference learning (e.g., Lattal, Mullen, \& Abel, 2003), fear conditioning (e.g., Quirk, 2002), instrumental learning (e.g., López-Romero, García-Barraza, \& Vila, 2010), drug seeking (e.g., Di Ciano \& Everitt, 2002), and consummatory behavior (e.g., Norris, Daniel, \& Papini, 2008).

To the best of our knowledge, only one previous study has assessed spontaneous recovery using flavor-nutrient learning. Tarner, Frieman, and Mehiel (2004, Experiment 2) found spontaneous recovery of CFP based on calories, using a differential training procedure (CS + paired with sucrose and CS- paired with saccharine) after 7, 14, and 21 days in hungry rats. It is difficult to determine the sources of the dissimilarities with our results, due to the differences in procedure and measures. Their training procedure consisted of 10 days during which the CSs were exposed for $23 \mathrm{~h}$ without additional available water, and CS + versus CS-, instead of CS + versus water preference, was assessed during pre- and postextinction tests. Perhaps the critical difference is that hungry rats were exposed to two sweetened CS flavors during training, only one of them paired with a nutrient. It is then possible that sweetness was not a good predictor of the nutrient and that the CS + flavor, rather than the compound with the taste of sucrose, becomes itself a signal for the nutrient. The flavor CS + would indeed behave as an extinguished stimulus, forming an excitatory association with the nutrient during training and extinguishing during posttraining flavor exposure. Note that such perceptual differentiation between flavor and sucrose is less likely in our procedure, in which the compound is a good predictor of the nutrient and would act as a unitary stimulus.

\section{Experiment 2: Reinstatement}

Another experimental manipulation that can recover the conditioned response after extinction is reinstatement, in which the extinguished response returns if the animal is merely reexposed to the US alone after extinction (Bouton, 2004). The aim of Experiment 2 was to test for the reinstatement effect after giving rats repeated two-bottle almond versus water tests, as in Experiment 1. The design is shown in Table 1 (Experiment 2). If the decrement in CFP is due to extinction, the extinguished preference should be restored by the simple reexposure to the original US (sucrose) in the absence of further presentations of the CS.

Method

Subjects and apparatus The subjects were 16 experimentally naïve female Wistar rats with a mean body weight of
$245 \mathrm{~g}$ at the start of the experiment. Housing, food, and water supply, as well as the apparatus and solutions, were the same as in Experiment 1.

Procedure Conditioning and flavor exposure ensued in the same manner as in Experiment 1. During the reinstatement phase, conducted 1 day after the last flavor exposure test, rats received $6 \mathrm{ml}$ of sucrose solution for $5 \mathrm{~min}$, followed by $30 \mathrm{~min}$ of water access; the next day, animals were tested for reinstatement with preference tests identical to those given during the flavor exposure phase.

\section{Results}

Conditioning phase The mean daily intakes of the almondsucrose compound consumed across the conditioning days were $3.93,5.89,5.9$, and $5.97 \mathrm{~g}$ for the simultaneous group. A similar pattern was found in the consumption of the sucrose in the serial group (means: 1.66, 4.77, 5.65, and $5.75 \mathrm{~g}$ ), with a lesser consumption on day 1 , as compared with the others. Finally, the mean consumptions of the almond in the serial group were 5.64, 5.55, 5.4, and $5.15 \mathrm{~g}$. Regarding differences between groups in the conditioning test (first flavor exposure test), the average preference ratio of the simultaneous group (.84) was significantly higher than that of the serial group (.67), $t(14)=9.32$, which was significantly higher than $.5, t(7)=3.33$.

Flavor exposure phase The results from the flavor exposure phase on both almond preference ratio and intake are shown in Fig. 2 (top and bottom left), demonstrating the average ratios and intakes in the two groups across this phase (2-day blocks). The 2 (group) $\times 5$ (block) ANOVA of the preference ratios revealed a main effect of group, $F(1,14)=18.98$, and block, $F(4,56)=4.47$. Regarding the main effect of group, the simultaneous group showed a greater preference than did the serial group. Regarding the main effect of block, flavor preference showed a decrement from block 1 to blocks 3 and 5. For more detailed exploration of preferences, the consumption of both almond and water were analyzed. The 2 (group) $\times 5$ (block) ANOVA of the almond intake revealed a main effect of group, $F(1,4)=9.35$, and block, $F(4,56)=$ 11.56. The statistical analysis revealed that the simultaneous group exhibited a higher consumption than did the serial group and that rats in both groups consumed more on block 1 than on blocks $2,3,4$, and 5 . A statistical analysis of water intake revealed that there was neither a main effect of group, $F(1,14)=2.01$, or block, $F(4,56)=2.37$, nor a group $\times$ block interaction, $F(4,56)=1.54$.

Reinstatement test Before the reinstatement test, all the rats were given $6 \mathrm{ml}$ of a sucrose solution that they consumed 
Fig. 2 Experiment 2. Top left: Average preference ratio of almond (as ratio of almond intake over total intake) on each of the five exposure blocks of 2 days for the simultaneous (SIM) and serial (SER) groups. Top right: Average preference ratio of almond on the last exposure to almond (test 10) and day of reinstatement test. Bottom left: Average intake of almond on each of the five exposure blocks of 2 days for both groups. Bottom right: Average intake of almond on the last exposure to almond and day of reinstatement test. Error bars represent SEMs
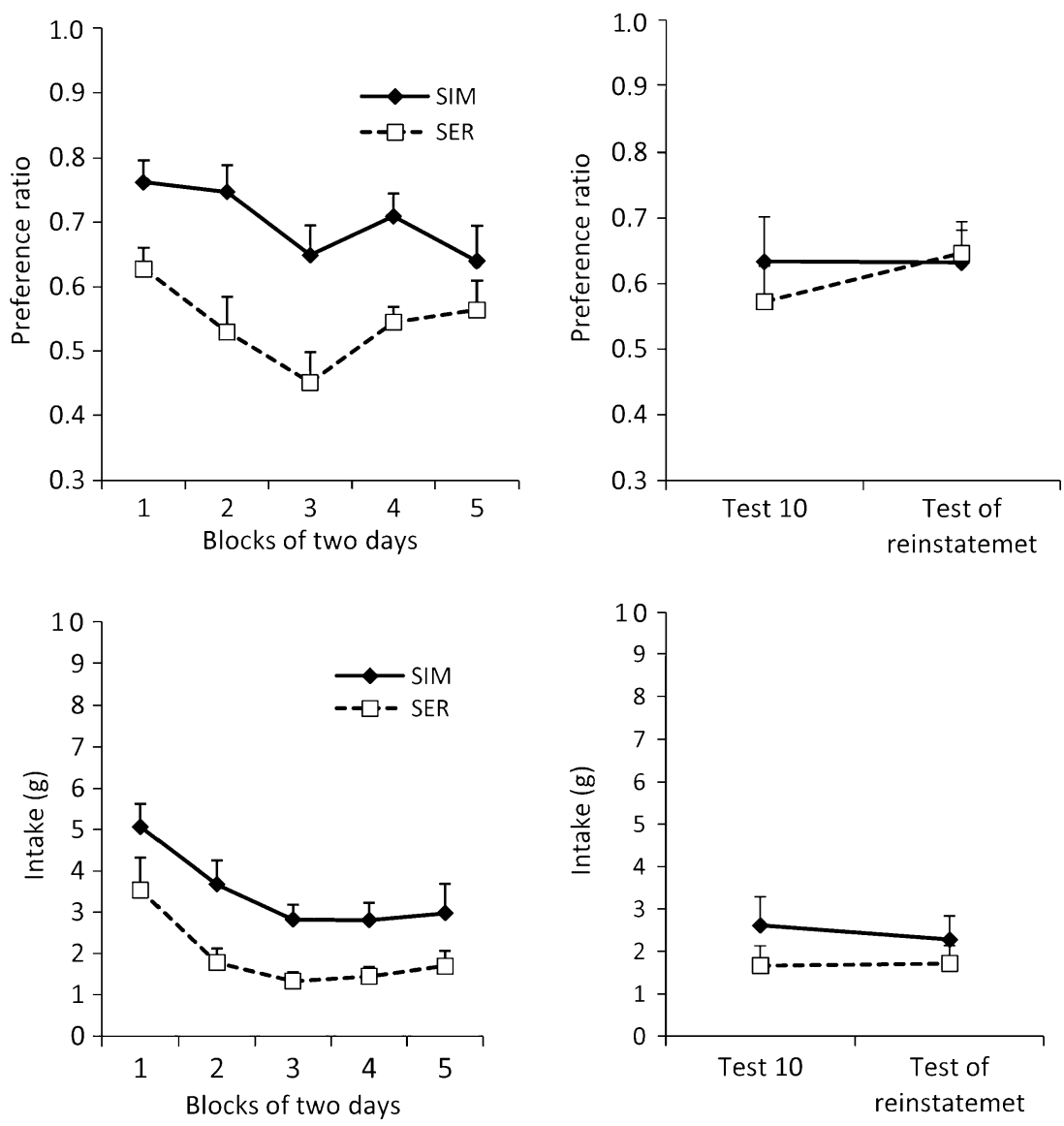

completely. Preference ratio and almond intake can be found in Fig. 2 (top and bottom right). Both groups were tested for reinstatement, comparing performance on the last flavor exposure test with that on the reinstatement test. The 2 (group) $\times 2$ (day) ANOVA of preference ratios failed to detect either main effects or a significant interaction, $F$ s $<1$. Similarly, the 2 (group) $\times 2$ (day) ANOVAs of the consumption revealed that there were neither significant main effects nor an interaction in either almond or water intake, $F \mathrm{~s}<2.27$.

\section{Discussion}

The conditioning data in Experiment 2 were consistent with those in Experiment 1, in which rats developed a higher preference for the flavor in the simultaneous group than in the serial group. In this experiment, the serial group exhibited a preference ratio greater than .5 , although this level of preference for this group was not observed in Experiments 1, 3, 4, and 5.

Regarding the flavor exposure phase, repeated nonreinforced presentation of almond reduced both preference ratio and intake from the first block to the last block. This happened, again, in both groups. However, there was no sign of reinstatement of preference or consumption of the almond after the US had been presented in a noncontingent fashion. It is true that this result involves accepting a null result, but this occurred despite the fact that a variety of different procedures readily produced reinstatement, including behavioral pharmacology preparations as a model of relapse (for a review, see, e.g., Katz \& Higgins, 2003), fear conditioning (e.g., Bouton \& Bolles, 1979), appetitive conditioning (e.g., Bouton \& Peck, 1989), and conditioned taste aversion (e.g., Schachtman, Brown, \& Miller, 1985).

\section{Experiment 3: US devaluation effect}

The null results observed in the previous experiments do not allow us to draw compelling conclusions about the status of the CS-US association after posttraining CS exposure. It could be the case that the parameters used were not appropriate to observe the recovery phenomena. Nevertheless, even when the unmasking procedures, such as spontaneous recovery or reinstatement, are effective in restoring extinguished performance, they are limited in the inferences they permit, since they are not especially powerful in estimating the strength of the association relative to associations that have not undergone extinction 
Table 2 Design for US-devaluation effect

\begin{tabular}{|c|c|c|c|c|c|c|c|}
\hline Groups & $\begin{array}{l}\text { Conditioning } \\
\text { Thirsty }\end{array}$ & $\begin{array}{l}\text { Pre-extinction } \\
\text { Thirsty \& } \\
\text { Hungry }\end{array}$ & $\begin{array}{l}\text { Conditioning } \\
\text { Test } \\
\text { Thirsty \& } \\
\text { Hungry }\end{array}$ & $\begin{array}{l}\text { Extinction } \\
\text { Thirsty \& } \\
\text { Hungry }\end{array}$ & $\begin{array}{l}\text { Devaluation } \\
\text { Thirsty \& } \\
\text { Hungry }\end{array}$ & $\begin{array}{l}\text { Sucrose } \\
\text { Devaluation } \\
\text { Test } \\
\text { Thirsty \& } \\
\text { Hungry }\end{array}$ & $\begin{array}{l}\text { Post- } \\
\text { Devaluation } \\
\text { Test } \\
\text { Thirsty \& } \\
\text { Hungry }\end{array}$ \\
\hline \multicolumn{8}{|l|}{ Experiment 3} \\
\hline $\begin{array}{l}\text { Ext_Dev } \\
\text { Ext_Nondev } \\
\text { Nonext_Dev } \\
\text { Nonext_Nondev }\end{array}$ & $2 \mathrm{~A}+$ & 3 water vs. water & A vs. water & $\begin{array}{l}6 \text { A vs. water } \\
6 \text { water vs. water }\end{array}$ & $\begin{array}{l}+\rightarrow \mathrm{LiCl} \text {, Water } \\
\text { water } \rightarrow \mathrm{LiCl},+ \\
+\rightarrow \mathrm{LiCl} \text {, Water } \\
\text { water } \rightarrow \mathrm{LiCl},+\end{array}$ & $\begin{array}{l}+ \text {, water } \\
\text { water, }+ \\
+, \text { water } \\
\text { water, + }\end{array}$ & A vs. water \\
\hline
\end{tabular}

$\mathrm{A}=\mathrm{CS}$ flavor; + = US sucrose; $\mathrm{LiCl}=$ lithium chloride; Ext_Dev, Ext_Nondev, Nonext_Dev, Nonext_Nondev = four conditions according to extinction factor (extinction or noextinction) and US-devaluation factor (devaluation or nondevaluation)

(Rescorla, 2001). The US devaluation technique provides such information. It is well known that an extinguished stimulus show the US devaluation effect and that the magnitude of the effect is indistinguishable from that observed with stimuli that had not received extinction (Delamater, 2004; Rescorla, 2001). This suggests that there is excellent preservation of the CS-US associations through an extinction procedure. Therefore, the US devaluation procedure was implemented in this study to further investigate whether the failure in finding spontaneous recovery and reinstatement phenomena was indeed due to a CS-US impairment after posttraining CS exposure.

This experiment had two aims. As in Harris et al.'s (2004, Experiment 3) study, the first aim was to determine whether rats exposed to almond after conditioning and prior to the development of a sucrose aversion would reject the almond on test in the same way as nonexposed rats. Unlike Harris et al., who used thirsty animals throughout the experiment, we trained animals thirsty, but they were also food deprived during the flavor exposure and subsequent phases, in a way similar to that in our previous experiments. Since the experimental evidence suggests that different motivational states at the time of testing may result in preferences based on different associations (Harris et al., 2000), we wanted to assess the absence of the sucrose devaluation effect in flavor-exposed animals when a motivational context change between conditioning and the other phases of the experiment was conducted.

The present experiment also introduced a potentially important difference from that of Delamater (2007, Experiment 3). Although, in both our experiment and that of Delamater (2007), animals were exposed to the target flavor and devaluated while hungry, in our experiment, rats were conditioned while thirsty. Thus, the main difference between our experiment and those of Harris et al. and Delamater is the introduction of a motivational change between conditioning and the rest of the phases.
Therefore, Experiment 3 examined the specificity of the effects of flavor exposure ${ }^{1}$ on particular components of conditioned flavor preference, using the US devaluation technique and the motivational states during training and flavor exposure used in the previous experiments. The design is shown in Table 2 and consists of a $2 \times 2$ factorial. Subjects in this experiment were initially trained with the simultaneous almond-sucrose compound while thirsty. Subsequently, animals were also food deprived; half the rats received exposures to the almond and water, while the remaining rats were exposed to water alone during the extinction phase (factor 1). Group Ext was given six repeated two-bottle almond versus water choice tests, whereas Group NonExt was given water in the two bottles during this time. Consumption of sucrose was then paired with illness produced by $\mathrm{LiCl}$ for half of the rats in each of these conditions, but not for the remaining rats, which received water paired with $\mathrm{LiCl}$ (factor 2). Finally, all rats were given an almond versus water choice test.

\section{Method}

Subjects and apparatus The subjects were 32 experimentally naïve female Wistar rats with a mean body weight of $260 \mathrm{~g}$ at the start of the experiment. Housing, solutions, apparatus, and general maintenance were the same as in Experiment1. During the sucrose devaluation phase, animals received intraperitoneal (i.p.) injections of $0.15 \mathrm{M}$ $\mathrm{LiCl}$ at $20 \mathrm{ml} / \mathrm{kg}$ of body weight.

Procedure Preconditioning (days 1-4) and conditioning procedures were similar to those used in Experiment 1, with

\footnotetext{
${ }^{1}$ Although we consider that the decrease in conditioned preference observed in this study is not due to extinction of the conditioned preference, for the sake of brevity in the denominations of the different groups, we are using the term only as a procedural manipulation consisting of the exposure of the CS outside the simultaneous compound after conditioning.
} 
the exception that there was no serial conditioning group and that two, rather than four, conditioning trials were conducted. The reason for this was to reduce exposure to sucrose before the devaluation phase and, thus, facilitate the development of an aversion to sucrose. During the conditioning phase, the CS flavor was presented forming a simultaneous compound with sucrose over days 5 and 6 . In each one, rats had access for $5 \mathrm{~min}$ to $6 \mathrm{ml}$ of almond mixed with sucrose. An additional 30-min period of water was allowed in this phase. After the conditioning phase, animals were both water and food deprived. The rats were given 3 days to accommodate to the food and water deprivation (days 7-9), by restricting food access to $90 \mathrm{~min}$ per day to both commodities. After 3 days of accommodation to food and water deprivation, the conditioning test (day 10) took place (a 30-min two-bottle test, $20 \mathrm{ml}$ of flavor A against $20 \mathrm{ml}$ of water).

The extinction was implemented over the next 6 days (days 11-16). Before this phase, animals were divided into two groups, Ext and NonExt, matched in preference ratio. During the extinction phase, group Ext was given 6 two-bottle almond versus water choice tests for $30 \mathrm{~min}$, while the other received 6 two-bottle exposures to water. Rats in each condition were further divided into two groups, Dev and NonDev, thus forming four groups ( $n=8$; see Table 2). The US devaluation took place during days 17 and 18, in which either the sucrose solution or water was presented in a single bottle. Animals in Groups Dev were given access to $20 \mathrm{ml}$ of sucrose solution for $15 \mathrm{~min}$, followed by a $\mathrm{LiCl}$ injection (i.p.), while on the second day they received 15-min access to water only. Animals in Groups NonDev were also injected with $\mathrm{LiCl}$ on the first day, but they were given access to water instead of sucrose, and only on the second day had access to $20 \mathrm{ml}$ of sucrose for $15 \mathrm{~min}$. Both groups received 90 min of water and food access at the end of each session.

The sucrose test took place on days 19 and 20, in which animals in Groups Dev drank sucrose on the first day and water on the second. Animals in Groups NonDev drank water on the first and sucrose on the second. Preference test after devaluation (postdevaluation test) took place on day 21. A postdevaluation test ensued in the same manner as the predevaluation test. Note that the predevaluation test was the conditioning test for the NonExt groups and the last extinction test for the Ext groups.

\section{Results}

Acquisition, extinction, and devaluation phases proceeded as expected.

Conditioning phase The intake of the almond-sucrose compound during the two acquisition trials increased significantly from a mean of $3.37 \mathrm{~g}$ on the first day to
$5.33 \mathrm{~g}$ on the second day, $t(31)=68.74$. Regarding the conditioning test, the average preference ratio for almond was .83 , very similar to the conditioning level obtained in previous experiments with four conditioning trials.

Extinction phase Preference ratios for almond decreased during the extinction phase in Group Ext. The statistical analysis revealed a decrement from a mean preference ratio of .76 on the first extinction test to .54 on the sixth, $t(15)=$ 13.71. This was due to a decrement in almond consumption from a mean of $4.75 \mathrm{~g}$ to $1.91 \mathrm{~g}, t(15)=14.58$, but not to changes in water consumption, $t(15)<1$.

Devaluation phase Analysis of the consumption of both almond and water are not reported for this phase, since a preliminary analysis showed a triple extinction $\times$ devaluation $\times$ test interaction in water consumption, $F(1,28)=$ 6.47; preference ratio therefore gave a clearer information of the relative almond/water consumption. The results from sucrose devaluation test are shown in Fig. 3 (top). The 2 (extinction) $\times 2$ (devaluation) ANOVA revealed a main effect of devaluation, $F(1,28)=128.47$. No other effects or interactions were significant.

The data of most interest are presented in Fig. 3 (bottom), which shows almond preference ratios for the four groups in pre- and postdevaluation tests. It is clear that the rats in Group NonExt_Dev showed a lesser preference for the flavor after sucrose devaluation, whereas the other three groups showed similar preference levels for the flavor before and after devaluation. The statistical analysis confirmed these impressions. The 2 (extinction) $\times 2$ (devaluation) $\times 2$ (test) ANOVA revealed main effects of extinction, $F(1,28)=16.93$, devaluation, $F(1,28)=6.7$, and test, $F(1,28)=7.36$, and significant extinction $\times$ test, $F(1,28)=16.13$, and extinction $\times$ devaluation $\times$ test, $F(1$, $28)=6.09$, interactions. To explore the three-way interaction, separate 2 (devaluation) $\times 2$ (test) ANOVAs were conducted for each extinction condition. The analysis revealed a significant devaluation $\times$ test interaction only in the NonExt condition, $F(1,14)=13.3$. No effects were significant in the extinction condition. The one-way ANOVA with day as factor showed a lower preference in Group NonExt_Dev in the postdevaluation test with respect to the predevaluation test, $F(1,7)=32.07$. Such a difference was not significant in Group NonExt_NonDev.

\section{Discussion}

The data from Experiment 3 confirmed that only Group NonExt_Dev showed a US devaluation effect. No decrease in almond preference after sucrose devaluation was observed among rats trained thirsty that had received 


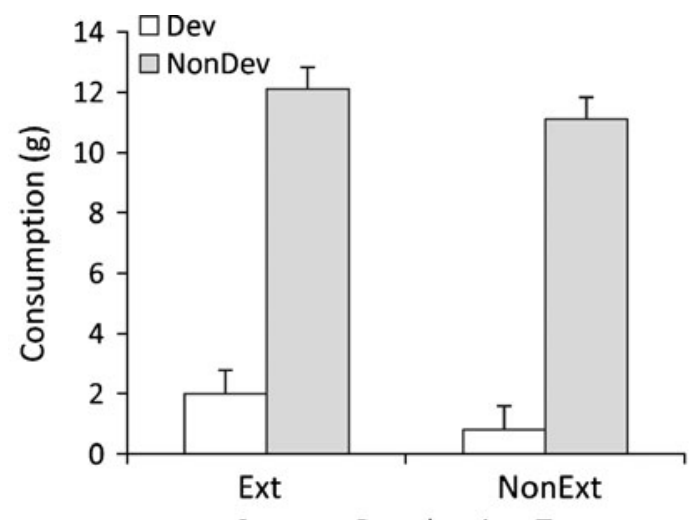

Sucrose Devaluation Test

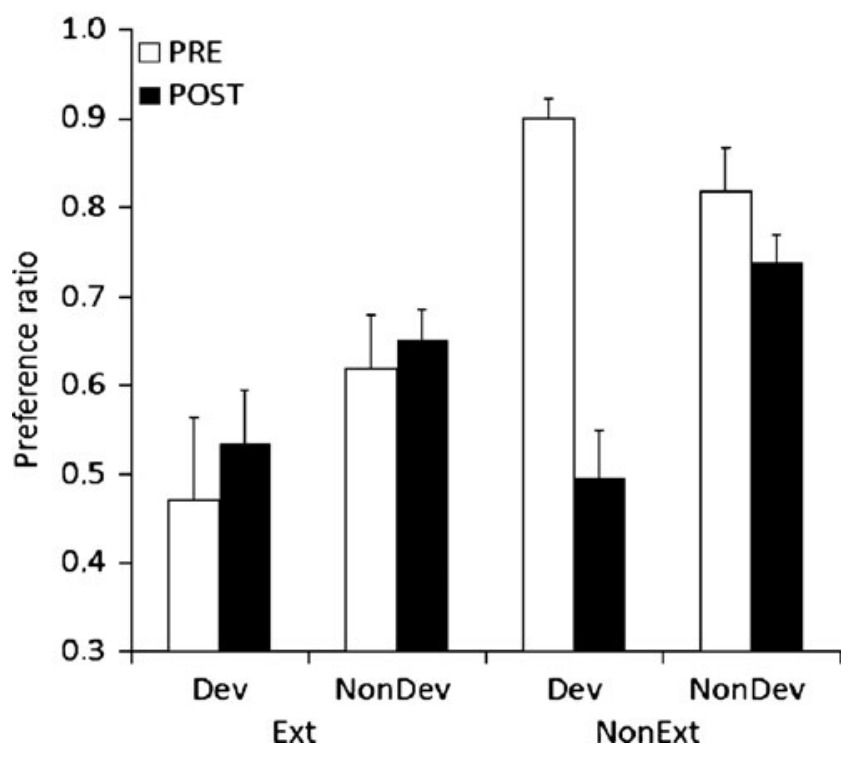

Fig. 3 Experiment 3. The top graph shows mean intake (g) of sucrose for the extinguished (Ext) or nonextinguished (NonExt) and devaluated (Dev) or nondevaluated (NonDev) conditions. The bottom shows the preference ratio for the flavor cue in the four conditions before (PRE) and after (POST) sucrose devaluation. Error bars represent SEMs

intervening exposures to almond while hungry prior to the establishment of a conditioned aversion to sucrose. These results agree with those in other studies in which no motivational shift was introduced between conditioning and flavor exposure, such as those reported by Harris et al. (2004) with thirsty rats and by Delamater (2007) with both thirsty and hungry rats; exposure to almond after training seems to weaken the association formed between the flavor and the sucrose, which is against the dominant view of extinction, as was commented on above. These results also suggest that the failure in getting spontaneous recovery and reinstatement might be due to the impairment of the CS-US association.

The proposal presented in this article, however, is that the decrease in CFP observed in the previous experiments was due to the development of inhibitory learning. The flavor might acquire the properties of a net inhibitor during posttraining flavor exposure when animals were thirsty and hungry. Thus, the aim of the following experiments was to obtain empirical evidence for this hypothesis. Experiments 4 and 5 were designed to obtain evidence of retardation and summation effects, respectively.

\section{Experiment 4: Retardation test}

In addition to an experimental group where rats were exposed to a simultaneous compound of a target flavor and sucrose during the conditioning phase (simultaneous), we used a control group (serial) where rats were given the same amount of the target flavor followed by sucrose, as in the previous experiments. The posttraining flavor exposure phase, however, consisted of four sessions in which the flavor was presented alone in a single bottle, instead of giving animals a two-bottle almond versus water test. This change in the exposure procedure was introduced to enhance flavor consumption in the simultaneous group and to make the exposure more effective. Given that acquisition rate depends on the degree of exposure to the stimulus and that, in CFP, the degree of exposure is determined by the consumption of the fluid, the control animals may have shown faster reacquisition simply because they had received less exposure to the flavor before the retardation test. In order to guarantee that the simultaneous and serial groups were similarly exposed to the target flavor after this second phase, and taking into account that the experimental animals drank more of the CS flavor during the 4 days of the exposure phase, animals in the serial group received an additional day of exposure to the flavor, whereas the simultaneous group received water. In the retardation test, and according to the study by Higgins and Rescorla (2004), we expected retardation in reacquisition in the simultaneous group, when compared with the acquisition rate of the serial group. Table 3 (Experiment 4) summarizes the design of this experiment.

\section{Method}

Subjects and apparatus The subjects were 16 experimentally naïve female Wistar rats with a mean body weight of $255 \mathrm{~g}$ at the start of the experiment. Animals were housed and maintained as in the previous experiments. The solutions and the procedure were also similar, with the exceptions mentioned below.

Procedure Before the start of the experiment, the animals were assigned to two weight-matched groups $(n=8)$. The water bottles were removed from the home cage $24 \mathrm{~h}$ before the start of the experiment. Rats were then adapted 
to a water deprivation schedule for 4 days (days 1-4), during which animals were allowed free access to water for 30 min on each morning in the tubes subsequently used to present the flavored solutions.

During the conditioning phase (days 5 to 6 and 8 to 9), rats in the simultaneous group were given $6 \mathrm{ml}$ of the almond-sucrose compound for $5 \mathrm{~min}(6 \mathrm{ml}$ were provided to guarantee a 5-ml consumption and compensate for possible fluid spillage), whereas rats in the serial group were given $6 \mathrm{ml}$ of almond presented for $5 \mathrm{~min}$, followed by 5 -min access to $6 \mathrm{ml}$ of sucrose. After each conditioning session, all animals had access to supplementary water for $30 \mathrm{~min}$. After the second conditioning trial and before the third, rats were given two-bottle almond versus water tests for $30 \mathrm{~min}$, each bottle containing $20 \mathrm{ml}$ of the corresponding fluid. This preference test was introduced in the hope that two conditioning trials would be sufficient to produce CFP in the simultaneous group, yet not so many as to produce latent inhibition in the serial group. However, unlike in Experiment 3, a total of four conditioning trials were finally necessary.

After the conditioning phase, rats were given 3 days (days 10-12) to adapt to the motivational conditions used in the conditioning test of food and water deprivation. On each of the 3 days, all groups received water in two tubes for $30 \mathrm{~min}$, followed by access to both food and water for $90 \mathrm{~min}$. The procedure for the conditioning test (day 13) involved a two-bottle almond versus water choice test for $30 \mathrm{~min}$, each bottle containing $20 \mathrm{ml}$ of the corresponding fluid, followed by limited access to food for $90 \mathrm{~min}$. In all two-bottle tests given in both this and the following experiment, the position of the bottles was counterbalanced within each group.

During the posttraining flavor exposure phase (days 1417), water bottles were replaced overnight and removed at
8:30 a.m. (during the light cycle), exposing animals to $20 \mathrm{ml}$ of CS flavor at 10:00 a.m. for $30 \mathrm{~min}$, using a single tube. This manipulation was intended so that rats would be hungry but not very thirsty, thus increasing the sensitivity of the measure; animals should drink as far as they associate the solution with calories, and not just because they were very thirsty (note that water was not concurrently available during the CS exposure sessions). The posttraining flavor exposure test (day 18) was conducted under the same conditions as the conditioning test. The rats, who were both thirsty and hungry, were given 1 two-bottle almond versus water test for $30 \mathrm{~min}$, each bottle containing $20 \mathrm{ml}$ of the corresponding fluid, followed by limited access to water for $90 \mathrm{~min}$, along with free access to food. In order to guarantee that both groups were similarly exposed to the target flavor before this test, the serial group received one additional exposure day (day 19) to $20 \mathrm{ml}$ of flavor for $30 \mathrm{~min}$, whereas the former received water.

The retardation test phase occurred over the next 9 days (days 20-28). It was run in three 3-day cycles. In each cycle, rats received two simultaneous almond-sucrose pairings on the first 2 days, and one almond versus water two-bottle test on the third. To equate the motivational conditions of the reacquisition phase to those of the conditioning phase, food was returned before the reacquisition training sessions and removed after the second day of reacquisition. Thus, rats were thirsty during the acquisition trials and hungry and thirsty during testing.

\section{Results}

Conditioning phase The mean daily intakes of almondsucrose compound consumed across the conditioning days were $1.52,5.18,5.32$, and $5.58 \mathrm{~g}$ for the simultaneous

Table 3 Designs for retardation and summation tests experiments

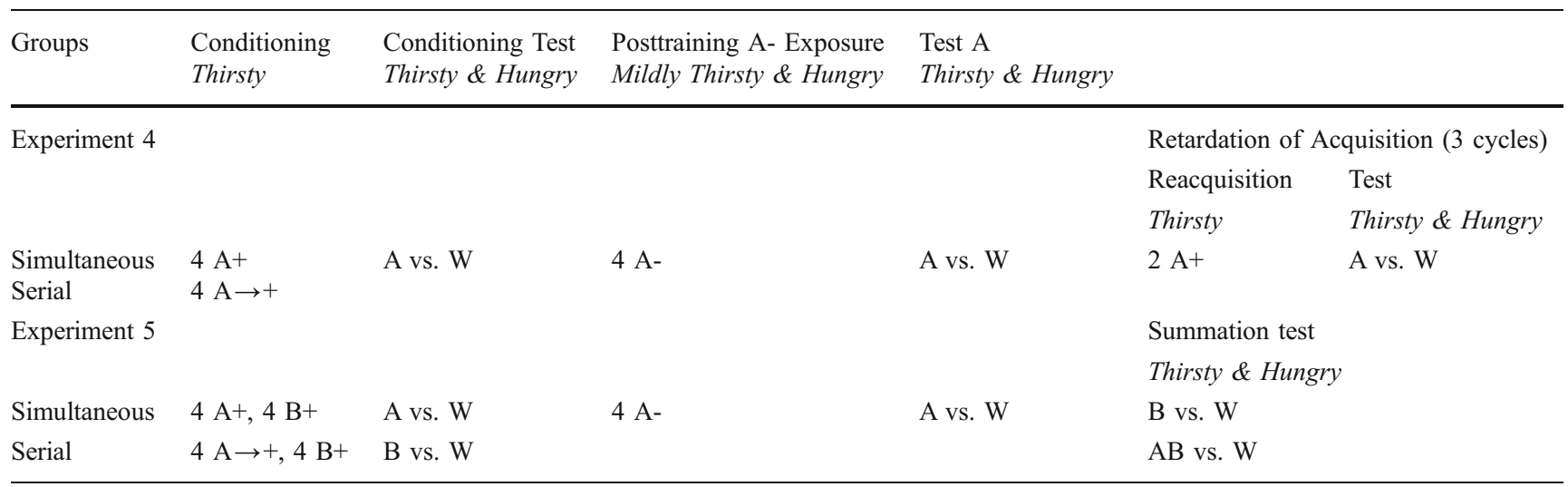

$\mathrm{A}$ and $\mathrm{B}=\mathrm{CS}$ flavors, counterbalanced; + = US sucrose; - = non reinforcement; $\mathrm{W}=$ water; Simultaneous = group given flavor A-sucrose compound during conditioning phase; Serial = control condition in which the sucrose solution was presented after the consumption of flavor A during conditioning phase 
group. A similar pattern was found in the serial group in the consumption of the almond solution (means: 4.81, $4.65,5.08$, and $5.01 \mathrm{~g}$ ) and of the sucrose solution (means: 2.52, 4.27, 4.7, and $5.15 \mathrm{~g}$ ). Repeated measures ANOVAs confirmed the effect of trial on almondsucrose consumption, $F(3,21)=100.82$, in the simultaneous group and on sucrose consumption, $F(3,21)=$ 12.99 , in the serial group, showing that rats consumed less of the solution on the first trial, revealing neophobia to the dense sucrose solutions. There were no significant differences among trials in the consumption of almond alone in the serial group, $F<1$. Regarding differences between groups in the conditioning test, the average preference ratio of the simultaneous group (.71) was significantly higher than that of the serial group (.46), $t(14)=12.24$. The average preference ratios for the flavor-A conditioning test, posttraining flavor exposure test, and retardation of acquisition test are shown in Fig. 4.

Posttraining flavor exposure phase The mean daily intakes of almond consumed across the four exposure days were $6.26,3.8,4.57$, and $3.25 \mathrm{~g}$ for the simultaneous group and $2.65,2.6,3.05$, and $2.38 \mathrm{~g}$ for the serial group. The 2 (group) $\times 4$ (day) ANOVA revealed a significant group $\times$ day interaction, $F(3,42)=8.47$. The statistical analysis revealed that the simultaneous group exhibited significantly lower consumption of almond on days 2, 3, 4, and 5 than on day 1 and that the serial group did not exhibit significant differences across days. Finally, the simultaneous group exhibited higher almond consumption than did the serial group on day 1. Regarding the posttraining flavor exposure test, no significant differences were found between the preference ratios of the simultaneous group (.48) and the serial group

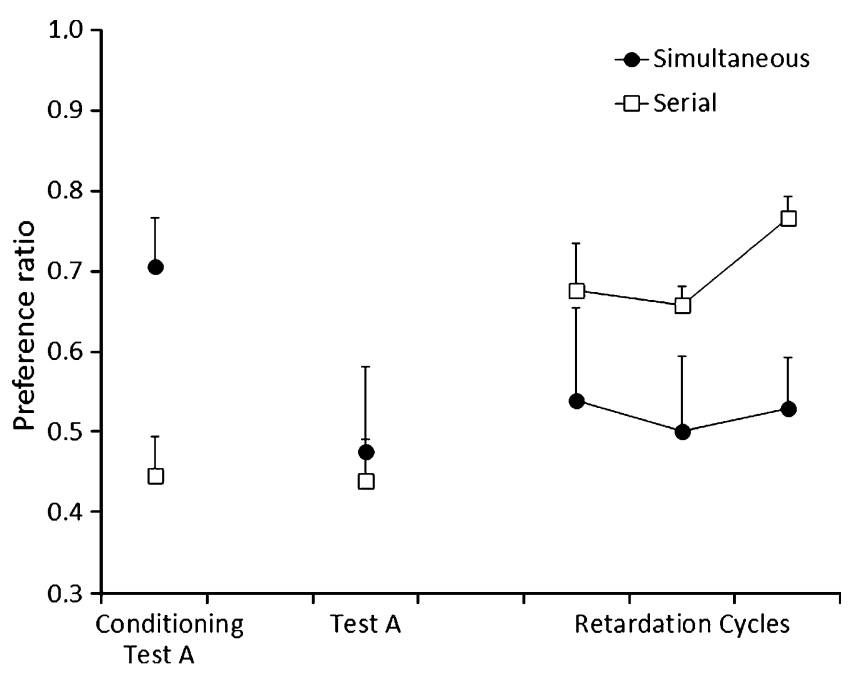

Fig. 4 Experiment 4. Average preference ratio of flavor $\mathrm{A}$ on conditioning test, posttraining flavor exposure test, and retardation tests for the simultaneous and serial groups. Error bars represent SEMs
(.44), $t(14)<1$. The mean intake of almond consumed was $17.89 \mathrm{~g}$ for the simultaneous group and $20.7 \mathrm{~g}$ for the serial group (adding the additional exposure day in order to guarantee that both groups were similarly exposed to the target flavor). There were no differences in almond intake between groups before the retardation test, $t(14)<1$.

Retardation test phase The results of the almond preference ratio test during this phase included three reacquisition trials. The 2 (group) $\times 3$ (trial) ANOVA of the preference ratios showed a main effect of group, $F(1,14)=4.7$, that revealed a higher preference in the serial group. It is important to note that the difference between groups emerged after the third reacquisition test. No other main effects or interactions were significant, $\mathrm{Fs}<1$.

\section{Discussion}

The simultaneous group acquired a conditioned preference for almond after training, whereas the serial group did not. During the CS exposure after training, the consumption of the flavor presented alone decreased in the first group, but not in the second. After this phase, the previous difference in preference ratio between groups observed after conditioning disappeared. Together, these data suggest that the CFP in the simultaneous group decreased as a result of the flavor exposure after training. However, the results of more interest are those of the retardation test.

The between-group comparison confirmed that reacquisition of preference after posttraining flavor exposure was retarded in the simultaneous group. It is important to note that both groups had a similar level of flavor exposition before this test; thus, it is difficult to attribute the difference in acquisition rate to differential latent inhibition. These results therefore are consistent with the suggestion that the flavor preference decrement in the present experiment was a result of inhibitory learning. The results also agree with the failure in retraining of the simultaneous group found by Higgins and Rescorla (2004).

\section{Experiment 5: Summation test}

Experiment 4 attempted to check the potential of a conditioned flavor that has been given the postsimultaneous conditioning flavor exposure to pass a summation test, as compared with a serial group. Table 3 provides a description of the design of Experiment 5. During the conditioning phase, thirsty animals received either initial simultaneous or serial training of a flavor (A) and sucrose and simultaneous conditioning of a second flavor (B), which served as the independent excitor for the summation 
test. Animals were subsequently food deprived and given nonreinforced exposures to flavor A. During the summation test, animals were given a choice between the excitor B presented in compound with flavor $\mathrm{A}$ in a two-bottle compound versus water test. All animals also received a two-bottle flavor B versus water choice to assess the preference governed by the test excitor. The order of these tests, which were conducted on different days, was counterbalanced. Thus, the present study was designed to examine the summation effect by within-subjects, as well as between-groups, comparisons. On the basis of the results of Experiment 4, we expected to find that the $\mathrm{AB}$ compound would cause less of a preference than would the excitor $\mathrm{B}$ alone in the simultaneous group, but not in the serial group. Additionally, no difference between groups was expected in the preference exhibited for flavor B, whereas a lesser preference for the $\mathrm{AB}$ compound was expected in the simultaneous group than in the serial group.

\section{Method}

Subjects and apparatus The subjects were 32 experimentally naïve female Wistar rats with a mean body weight of $251 \mathrm{~g}$ at the start of the experiment. Animals were housed and maintained in a way similar to that in Experiment 4. The solutions were those in Experiment 4, with one exception. In addition to flavor A and sucrose $(20 \%[\mathrm{w} / \mathrm{v}])$, a flavor B was used; flavor $\mathrm{A}$ and $\mathrm{B}$ were almond or vanilla in tap water at $1 \%$ ( $\mathrm{vol} / \mathrm{vol}$ ) concentration, counterbalanced (almond and vanilla flavorings supplied by SuperCook, Leeds, U.K.). Fresh solutions were prepared every day, using room temperature tap water. Animals were fluid and food deprived as detailed below.

Procedure Before the start of the experiment, the animals were assigned to two weight-matched groups $(n=16)$. The rats were adapted to a water deprivation schedule for 4 days (days 1-4), removing the water bottles from the home cages $24 \mathrm{~h}$ before the start of the experiment. During these 4 days, the animals were allowed free access to water for $30 \mathrm{~min}$ each morning from the drinking tubes subsequently used to present the flavored solutions.

During the conditioning phase (days 5-12), group simultaneous received conditioning to flavor B on days 5, 6 , 9, and 12, consisting of $5-\mathrm{min}$ access to $6 \mathrm{ml}$ of a simultaneous compound of flavor B and sucrose solution. On days $7,8,10$, and 11 , they received $6 \mathrm{ml}$ of simultaneous compound of flavor A and sucrose solution for $5 \mathrm{~min}$. The conditioning schedule for the serial group was similar, except that the 5 -min access to $6 \mathrm{ml}$ of flavor A were followed by 5 -min access to $6 \mathrm{ml}$ of sucrose (serial A $\rightarrow+$ presentations). After each conditioning session, all animals had access to supplementary water for $30 \mathrm{~min}$.
After this conditioning phase, the rats were given 3 days (days 13-15) to adapt to the test conditions to be used in the conditioning test of food and water deprivation as in Experiment 4. The procedure for the conditioning test for flavors A and B (days 16 and 17) was 1 two-bottle flavor versus water test for $30 \mathrm{~min}$ each day, and each bottle containing $20 \mathrm{ml}$ of the corresponding fluid in counterbalanced order.

The posttraining flavor exposure phase (days 18-21) and posttraining flavor exposure test (day 22) ensued in the same manner as in Experiment 1.

The summation test occurred over the following 2 days (days 23 and 24) under food and water deprivation. As was mentioned above, the order of flavor presentation during summation tests across 2 days, $\mathrm{B}$ or $\mathrm{AB}$, was counterbalanced.

\section{Results}

Conditioning phase The mean daily intakes of the flavorB-sucrose compound consumed across the conditioning days were $3.73,5.36,5.6$, and $5.56 \mathrm{~g}$ for the simultaneous group and 3.76, 5.32, 5.46, and $5.73 \mathrm{~g}$ for the serial group. The 2 (group) $\times 4$ (trials) ANOVA of the flavor-B-sucrose intake revealed a significant main effect of trial, $F(3,90)=$ 52.6. The statistical analysis revealed a lower consumption on the first day. The mean daily intakes of the flavor-Asucrose compound consumed across the conditioning days were 5.12, 5.46, 5.55, and $5.45 \mathrm{~g}$ for the simultaneous group. A repeated measures ANOVA confirmed an effect of trial, $F(3,45)=3.51$, showing a lower consumption on the first day, as compared with that on the third. A similar pattern was found for the serial group in the consumption of the flavor A solution, $F(3,45)=7.96$ (means: 4.39, 5.13, 5.05 , and $5.14 \mathrm{~g})$, and of the sucrose, $F(3,45)=4.59$ (means: 4.63, 5.27, 5.28, and $5.31 \mathrm{~g}$ ).

Regarding differences between groups in the conditioning of flavor $\mathrm{A}$, the average preference ratio of the simultaneous group (.73) was significantly higher than that of the serial group (.43), $t(30)=49.71$; regarding comparison between groups in the conditioning of flavor $\mathrm{B}$, no differences were found between the average preference ratio of the simultaneous group (.77) and that of the serial group (.72), $t(30)=2.69$. The average preference ratios for the flavor $\mathrm{A}$ and $\mathrm{B}$ conditioning test, posttraining flavor-A exposure test, and summation test are shown in Fig. 5.

Posttraining flavor exposure phase The mean daily intakes of almond consumed across the four exposure days were $6.3,5.12,3.19$, and $2.4 \mathrm{~g}$ for the simultaneous group and $4.67,3.31,3.36$, and $2.32 \mathrm{~g}$ for the serial group. The 2 


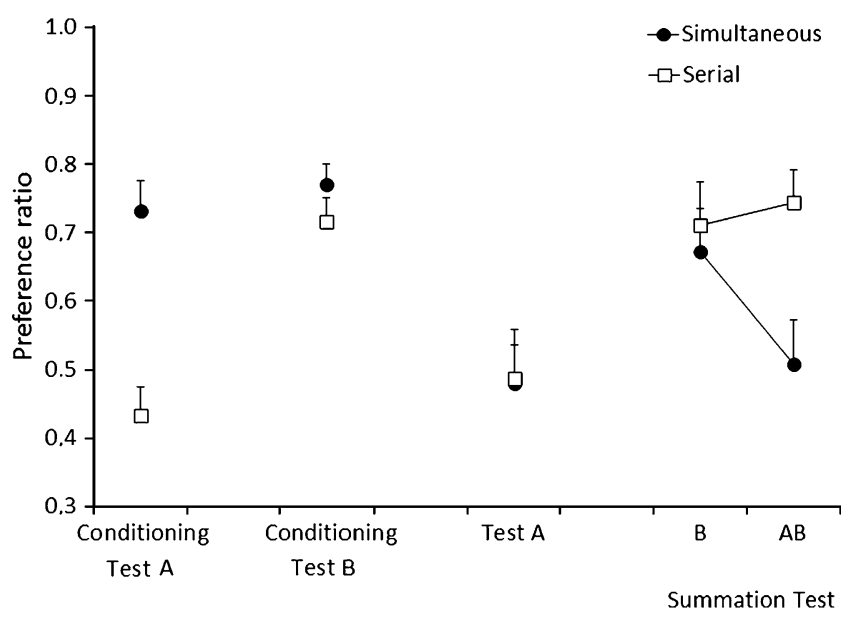

Fig. 5 Experiment 5. Average preference ratio of conditioning test for flavor A, conditioning test for flavor B, posttraining flavor A exposure test, and summation test for the simultaneous and serial groups. Error bars represent SEMs

(group) $\times 4$ (day) ANOVA of the flavor A intake revealed a significant group $\times$ day interaction, $F(3,90)=5.34$. The statistical analysis revealed that the simultaneous group exhibited significantly lower consumption of flavor A on days 3 and 4 than on day 1 and that the serial group exhibited significantly lower consumption on days 2,3 , and 4 than on day 1 . Finally, the simultaneous group exhibited higher flavor A consumption than did the serial group on days 1 and 2. Regarding the posttraining flavor A exposure test, no significant differences were found between the preference ratio of the simultaneous group (.48) and the serial group (.48), $t(30)<1$.

Summation test The 2 (group) $\times 2$ (trial) ANOVA of the preference ratios showed a significant group $\times$ trial interaction, $F(1,30)=7.28$, which once explored, revealed a lower preference for the $\mathrm{AB}$ compound in the simultaneous group than in the serial group, $t(30)=17.58$. No differences between groups were found in preference for flavor B. Only the simultaneous group showed a significant decrement in consumption of the $\mathrm{AB}$ compound, as compared with that of flavor B alone, $\mathrm{t}(15)=11.45$.

\section{Discussion}

The simultaneous group acquired a conditioned preference for flavor A, whereas the serial group did not; both, however, showed a similar conditioned preference for flavor B. During the flavor A exposure after training, both groups decreased their consumption of the flavor presented alone. After this phase, the previously observed betweengroup difference in preference ratio for flavor A disappeared. Together, these data suggest that the CFP in the simultaneous group decreased as a result of the flavor exposure after training. Regarding the summation test, there was no decrease in preference for flavor B when presented forming a compound with flavor $\mathrm{A}$ in the serial group, an effect that was detected in the simultaneous group. The absence of an effect in the serial group indicates that the decrease in preference for the compound in the simultaneous group was not due to a generalization decrement.

\section{General discussion}

Findings obtained in the present study suggest that the decrease in preference observed in hungry rats after flavor exposure-using both two-bottle flavor versus water (Experiments 1-3) and one-bottle (Experiments 4 and 5) procedures-following simultaneous flavor-sucrose conditioning might not be due to conditioned preference extinction; at least we consider that extinction acts in a completely different manner in this paradigm. The results supporting this hypothesis were as follows. Regarding extinction-related phenomena, no evidence of spontaneous recovery was found when the flavor preference was tested 2 weeks after the flavor exposure phase (Experiment 1). No evidence of reinstatement was found either when the US was reexposed after the flavor exposure phase (Experiment 2). Finally, only the nonextinguished and devalued group showed a sucrose devaluation effect, while the extinguished and devalued group failed to show it (Experiment 3).

Given that the proposal presented in this article considers that the flavor becomes a net conditioned inhibitor, Experiments 4 and 5 were aimed at finding empirical evidence supporting this hypothesis. They showed that a flavor paired simultaneously with a nutrient during conditioning in thirsty rats acquired inhibitory properties after being subsequently presented alone repeatedly to water- and fooddeprived animals. Evidence consisted of both reacquisition retardation of the conditioned preference after flavor exposure (Experiment 4; see also Higgins \& Rescorla, 2004) and reduction in the preference for an excitor flavor when it was presented forming a compound with the target flavor (Experiment 5). Retardation and summation tests are routinely regarded as empirical proof for conditioned inhibition (Rescorla, 1969). These results suggest that the decrease in preference observed in thirsty and hungry animals exposed to the CS after simultaneous training is produced by the acquisition by the flavor of the properties of a net inhibitor. There was not such evidence in animals trained with a serial procedure, which produced, if anything, a poor level of preference (only in Experiment 2), which could have been due either to weak conditioning or to increased experience with the flavor (i.e., mere exposure effect). 
An attempt to deal with the simultaneous group results from an elemental approach may propose that while drinking the flavor-sucrose compound, thirsty rats may learn three distinct associations: almond-taste, almondcalorie, and probably an association between almond and the hedonic reactions resulting from the ingestion of the compound (see Harris et al., 2004). Therefore, the procedure used in this study (i.e., AT+; A-) is not the usual extinction procedure, in which a single cue is usually followed by the US before the cue is presented alone (e.g., $\mathrm{A} \rightarrow++$; A-). After experimental extinction, the stimulus acquires two different and opposite associations, both of which seem to subsist and compete for performance (Bouton, 1993). However, in the AT+; A- procedure, more than ambiguity, there is redundancy in the prediction of the outcome, which is solved in the second phase of the procedure. Consider this phase, in which the flavor is repeatedly presented outside the flavor-sucrose compound - for the first time - after conditioning, the rats now being thirsty and hungry. According to Harris et al. (2000), hungry rats base their preference for almond on its association with the calories provided by sucrose, but the nutrient calories, as well as the sweetness, are absent. That the almond-sweetness association was impaired after this treatment was revealed by the absence of a US devaluation effect in Experiment 3. It is reasonable to think that the almond-nutrient association was also impaired (see Delamater, 2007). This probably applies to almond-hedonic reactions as well (Dwyer, Pincham, Thein, \& Harris, 2009). In fact, if we consider that during training, there is a sensory compound (almond + sweetness), followed by both nutrient properties and hedonic reactions, presenting the almond alone during testing could activate the representations of both US properties, which would be absent at that moment. These conditions are thought to produce inhibitory learning.

Similar to the formation of a unitary flavor-taste representation during simultaneous flavor conditioning proposed by Higgins and Rescorla (2004), explained in more detail in the introduction, Pearce (2002) offered an explanation of CFP that involves a configural representation of the flavor-taste sensory cues. He suggested that when a neutral flavor is simultaneously paired with an attractive flavor, both stimuli excite a configural representation of the compound, comprising elements of both stimuli. Subsequent presentation of one element of the compound via activation of the configural unit activates the sensory input unit of the other. Therefore, the presentation of the neutral flavor will activate the input unit for the US taste through the configural unit. Because of its innate hedonic value, the US taste will be connected to an output unit (i.e., palatability) that will be responsible for sustaining preference. Once the configural representation is formed, the nonreinforced flavor CS exposure should not affect its ability to activate the configural flavor-US taste unit, and generalization of hedonic value should be relatively unaffected by an extinction procedure. Additionally, a more complex network develops if the neutral flavor is presented in solution with a palatable nutrient (e.g., sucrose), since the configural unit will gradually enter into an excitatory association with the nutritive consequences of consuming the solution (Pearce, 2002, Note 4). However, repeated exposure to one element by itself, such as posttraining flavor exposure, will promote a perceptual differentiation of the component from the compound. This perceptual differentiation might be enhanced because the compound and its component (i.e., flavor-taste compound vs. the flavor alone) signal opposed outcomes (i.e., presence vs. absence of nutrient) (Pearce, 2002). If a representation of the flavor component differentiated from the compound during the CS exposure phase, it is then possible that the flavor becomes a signal of the absence of the nutrient-for instance, according to Wagner's model, as explained in the introduction.

To the best of our knowledge, there are no previous studies that have evaluated the possibility of the development of conditioned inhibition after posttraining CS exposure in nutrient-based CFP. Rather, the decrease in preference has been interpreted as being due to conditioned preference extinction. Since the result of our assessment is positive, it is necessary to consider whether these data support that an extinguished stimulus can act as a net inhibitor. Although previous studies using conditioned taste aversion have reported evidence in favor of the acquisition of such proprieties for an extinguished CS (Calton, Mitchell, \& Schachtman, 1996; Hart, Bourne, \& Schachtman, 1995), more refined designs have proved that this has not been the case (e.g., Aguado, de Brugada, \& Hall, 2001; see also Brooks, Bowker, Anderson, \& Palmatier, 2003). Modern theories of extinction suppose that some form of inhibitory learning occurs during extinction (e.g., Bouton, 1991; Pearce \& Hall, 1980; Rescorla \& Wagner, 1972; Wagner, 1981), but none of them supposes that the extinction will convert the CS into a net inhibitor, either because the associative strength is reduced to zero through a process of "unlearning" or because the inhibitory association matches in its effects those produced by the previous excitatory association (Aguado et al., 2001).

If the decrease in preference found in these experiments is due to the acquisition by the flavor of the properties of a net inhibitor, there would be no need to consider that extinction acts under different rules in this paradigm, as has previously been suggested (e.g., Delamater, 2007). On the other hand, the question of what is the particular mechanism that produces conditioned inhibition needs to be answered, an issue that falls beyond the scope of the 
present experiments, aimed partially at finding empirical evidence of conditioned inhibition, but not at analyzing the precise mechanism underlying such learning. Therefore, we recognize that at this point, such an analysis has to be rather speculative. The present results do not allow us to assess the relative impact of the mechanisms outlined above. More research is needed to specify the precise underlying learning mechanisms.

The fact that conditioned inhibition in nutrient-based flavor learning is possible has recently been reported by Boakes, Colagiuri, and Mahon (2010; see also GarciaBurgos \& González, 2011). They found that hungry rats learned to avoid a flavor that signaled the absence of an otherwise expected nutrient, using both an unpaired condition (see also Harris et al., 2000) and a differential conditioning procedure, an effect they have termed the "missing calorie effect." Since the flavor also passed retardation and summation tests, the authors considered it as a conditioned inhibitor.

The experiments presented here provide empirical evidence showing that a flavor previously paired simultaneously with sucrose acquired inhibitory properties after being presented alone when animals were hungry; the flavor showed retardation in subsequent reacquisition and a decrease in the preference for an excitor when presented in a simultaneous compound with it. To which extent similar results may be found in other, more conventional paradigms of Pavlovian conditioning is an issue subject to empirical verification, but the principles under which conditioned inhibition might arise could be common to these paradigms.

Acknowledgements This research was supported by CICYT Grant PSI2009-10627 (MICINN, Spain) and Grant HUM-02763 (Junta de Andalucía, Spain), partially funded by FEDER funding. We gratefully thank Professors R. A. Boakes, G. Hall, and F. Westbrook for suggestions on previous versions of the manuscript, F. Garzón for technical assistance, and I. Evans for language editing of the manuscript.

\section{References}

Aguado, L., de Brugada, I., \& Hall, G. (2001). Tests for inhibition after extinction of a conditioned stimulus in the flavour aversion procedure. Quarterly Journal of Experimental Psychology, 54B, 201-217.

Albertella, L., \& Boakes, R. A. (2006). Persistence of conditioned flavor preferences is not due to inadvertent food reinforcement. Journal of Experimental Psychology. Animal Behavior Processes, 32, 386-395.

Boakes, R. A., Colagiuri, B., \& Mahon, M. (2010). Learned avoidance of flavors signaling reduction in a nutrient. Journal of Experimental Psychology. Animal Behavior Processes, 36, 117-125.

Bouton, M. E. (1991). Context and retrieval in extinction and in other examples of interference in simple associative learning. In L. W. Dachowski \& C. F. Flaherty (Eds.), Current topics in animal learning: Brain, emotion, and cognition (pp. 25-53). Hillsdale, NJ: Erlbaum.
Bouton, M. E. (1993). Context, time, and memory retrieval in the interference paradigms of Pavlovian learning. Psychological Bulletin, 114, 80-99.

Bouton, M. E. (2004). Context and behavioral processes in extinction. Learning and Memory, 11, 485-494.

Bouton, M. E., \& Bolles, R. C. (1979). Contextual control of the extinction of conditioned fear. Learning and Motivation, 10, $455-466$.

Bouton, M. E., \& Peck, C. A. (1989). Context effects on conditioning, extinction, and reinstatement in an appetitive conditioning preparation. Animal Learning \& Behavior, 17, 188-198.

Brooks, D. C., Bowker, J. L., Anderson, J. E., \& Palmatier, M. I. (2003). Impact of brief or extended extinction of a taste aversion on inhibitory associations: Evidence from summation, retardation, and preference tests. Learning \& Behavior, 31, 69-84.

Calton, J. L., Mitchell, K. G., \& Schachtman, T. R. (1996). Conditioned inhibition produced by extinction of a conditioned stimulus. Learning and Motivation, 27, 335-361.

Capaldi, E. D., Campbell, D. H., Sheffer, J. D., \& Bradford, J. P. (1987). Conditioned flavor preferences based on delayed caloric consequences. Journal of Experimental Psychology. Animal Behavior Processes, 13, 150-155.

Capaldi, E. D., Myers, D. E., Campbell, D. H., \& Sheffer, J. D. (1983). Conditioned flavor preferences based on hunger level during original flavor exposure. Animal Learning \& Behavior, 11, 107-115.

Delamater, A. R. (1996). Effects of several extinction treatments upon the integrity of Pavlovian stimulus-outcome associations. Animal Learning \& Behavior, 24, 437-449.

Delamater, A. R. (2004). Experimental extinction in Pavlovian conditioning: Behavioural and neuroscience perspectives. Quarterly Journal of Experimental Psychology, 57B, 97-132.

Delamater, A. R. (2007). Extinction of conditioned flavor preferences. Journal of Experimental Psychology. Animal Behavior Processes, 33, 160-171.

Delamater, A. R., \& Oakeshott, S. (2007). Learning about multiple attributes of reward in Pavlovian conditioning. Annals of the New York Academy of Sciences, 1104, 1-20.

Díaz, E., \& De la Casa, L. G. (2011). Extinction, spontaneous recovery and renewal of flavor preferences based on taste-taste learning. Learning and Motivation, 42, 64-75.

Di Ciano, P., \& Everitt, B. J. (2002). Reinstatement and spontaneous recovery of cocaine-seeking following extinction and different durations of withdrawal. Behavioural Pharmacology, 13, 397-405.

Dwyer, D. M., Pincham, H. L., Thein, T., \& Harris, J. A. (2009). A learned flavor preference persists despite the extinction of conditioned hedonic reactions to the cue flavors. Learning \& Behavior, 37, 305-310.

Drucker, D. B., Ackroff, K., \& Sclafani, A. (1994). Nutrientconditioned flavor preference and acceptance in rats: Effects of deprivation state and non-reinforcement. Physiology and Behavior, 56, 701-707.

Elizalde, G., \& Sclafani, A. (1990). Flavor preference conditioned by intragastric Polycose: A detailed analysis using an electronic esophagus preparation. Physiology \& Behavior, 47, 63-77.

Fedorchak, P. M. (1997). The nature and strength of caloric conditioning. In M. E. Bouton \& M. S. Fanselow (Eds.), Learning, motivation, and cognition: The functional behaviorism of Robert C. Bolles (pp. 255-269). Washington, DC: American Psychological Association.

Garcia-Burgos, D., \& González, F. (2011). Evidence of predictive learning in nutrient-based flavor conditioning in rats using the summation test for conditioned inhibition. Psicothema, 23, 759-764.

González, F., de Brugada, I., \& Gil, M. (2008). Factores motivacionales y emocionales implicados en la preferencia condicionada al sabor utilizando sacarosa como EI [Motivational and emotional factors involved in conditioned flavor preference using sucrose as 
US]. In I. Etxebarria et al. (Eds.), Emoción y motivación: Contribuciones actuales (Vol. 2, pp. 45-56). Madrid: Asociación de Motivación y Emoción.

Harris, J. A., Gorissen, M. C., Bailey, G. K., \& Westbrook, R. F. (2000). Motivational state regulates the content of learned flavor preferences. Journal of Experimental Psychology. Animal Behavior Processes, 26, 15-30.

Harris, J. A., Shand, F. L., Carroll, L. Q., \& Westbrook, R. F. (2004). Persistence of preference for a flavor presented in simultaneous compound with sucrose. Journal of Experimental Psychology. Animal Behavior Processes, 30, 177-189.

Hart, J. A., Bourne, M. J., \& Schachtman, T. R. (1995). Slow reacquisition of a conditioned taste aversion. Animal Learning \& Behavior, 23, 297-303.

Higgins, T., \& Rescorla, R. A. (2004). Extinction and retraining of simultaneous and successive flavor conditioning. Learning \& Behavior, 32, 213-219.

Holman, E. W. (1975). Immediate and delayed reinforcers for flavor preferences in rats. Learning and Motivation, 6, 91-100.

Katz, J. L., \& Higgins, S. T. (2003). The validity of the reinstatement model of craving and relapse to drug use. Psychopharmacology, $168,21-30$.

Lattal, K. M., Mullen, M. T., \& Abel, T. (2003). Extinction, renewal, and spontaneous recovery of a spatial preference in the water maze. Behavioral Neuroscience, 117, 1017-1028.

López-Romero, L. J., García-Barraza, R., \& Vila, J. (2010). Spontaneous recovery in human instrumental learning: Integration of information and recency to primacy shift. Behavioural Processes, 84, 617-621.

Lucas, F., \& Sclafani, A. (1989). Flavor preferences conditioned by intragastric fat infusions in rats. Physiology \& Behavior, 46, 403412.

Norris, J. N., Daniel, A. M., \& Papini, M. R. (2008). Spontaneous recovery of consummatory behavior, but not of consummatory successive negative contrast. Learning and Motivation, 39, 296-312.

Pearce, J. M. (2002). Evaluation and development of a connectionist theory of configural learning. Animal Learning \& Behavior, 30, 73-95.

Pearce, J. M., \& Hall, G. (1980). A model for Pavlovian learning: Variations in the effectiveness of conditioned but not of unconditioned stimuli. Psychological Review, 87, 532-552.

Pérez, C., Lucas, F., \& Sclafani, A. (1998). Increased flavor acceptance and preference conditioned by the postingestive actions of glucose. Physiology and Behavior, 64, 483-492.
Quirk, G. J. (2002). Memory for extinction of conditioned fear is long-lasting and persists following spontaneous recovery. Learning and Memory, 9, 402-407.

Rescorla, R. A. (1969). Pavlovian conditioned inhibition. Psychological Bulletin, 72, 77-94.

Rescorla, R. A. (1996). Preservation of Pavlovian associations through extinction. Quarterly Journal of Experimental Psychology, 49, 245-258.

Rescorla, R. A. (2001). Experimental extinction. In R. R. Mowrer \& S. B. Klein (Eds.), Handbook of contemporary learning theories (pp. 119-154). Mahwah, NJ: Erlbaum.

Rescorla, R. A., \& Wagner, A. R. (1972). A theory of Pavlovian conditioning: Variations in the effectiveness of reinforcement and non-reinforcement. In A. H. Black \& W. F. Prokasy (Eds.), Classical conditioning II: Current research and theory (pp. 64 99). New York: Appleton-Century-Crofts.

Ricker, S. T., \& Bouton, M. E. (1996). Reacquisition following extinction in appetitive conditioning. Animal Learning \& Behavior, 24, 423-436.

Rosas, J. M., \& Bouton, M. E. (1996). Spontaneous recovery after extinction of a conditioned taste aversion. Animal Learning \& Behavior, 24, 341-348.

Rozin, P., \& Schulkin, J. (1990). Food selection. In E. M. Stricker (Ed.), Handbook of behavioral neurobiology: Neurobiology of food and fluid intake (Vol. 10, pp. 297-328). New York: Plenum.

Rozin, P., \& Zellner, D. A. (1985). The role of Pavlovian conditioning in the acquisition of food likes and dislikes. Annals of the New York Academy of Sciences, 443, 189-202.

Schachtman, T. R., Brown, A. M., \& Miller, R. R. (1985). Reinstatement-induced recovery of a taste- $\mathrm{LiCl}$ association following extinction. Animal Learning \& Behavior, 13, 223-227.

Sclafani, A. (1991). Conditioned food preferences. Bulletin of the Psychonomic Society, 29, 256-260.

Sclafani, A., \& Nissenbaum, J. W. (1988). Robust conditioned flavor preference produced by intragastric starch infusions in rats. American Journal of Physiology, 255, R672-R675.

Tarner, N., Frieman, J., \& Mehiel, R. (2004). Extinction and spontaneous recovery of a conditioned flavor preference. Learning and Motivation, 35, 83-101.

Wagner, A. R. (1981). SOP: A model of automatic memory processing in animal behavior. In N. E. Spear \& R. R. Miller (Eds.), Information processing in animals:Memory mechanisms (pp. 5-47). Hillsdale, NJ: Erlbaum. 